\title{
Superação de dormência tegumentar em sementes de Senna silvestris (Vell.) H. S. Irwin \& Barneby
}

\author{
Álisson Sobrinho Maranho * \\ Ary Vieira de Paiva \\ Centro de Ciências Biológicas e da Natureza, Universidade Federal do Acre \\ Distrito Industrial, CEP 69.915-900, Rio Branco - AC, Brasil \\ * Autor para correspondência \\ alissonsobrinho@hotmail.com
}

Submetido em 14/09/2011

Aceito para publicação em 16/01/2012

\section{Resumo}

Senna silvestris (Vell.) H. S. Irwin \& Barneby é uma planta de hábito arbóreo nativa do Brasil, com potencial para arborização urbana, cujas sementes apresentam dormência imposta pelo tegumento. Considerando a necessidade de melhor conhecimento das espécies florestais nativas e, mais especificamente, dos processos de superação de dormência, esse estudo teve por objetivo verificar o comportamento de sementes de S. silvestris submetidas a diferentes tempos de exposição (0, 0,5, 3,0 e 5,0 minutos) ao ácido sulfúrico concentrado (98\%) com quatro repetições de 25 sementes em delineamento inteiramente casualizado. As variáveis avaliadas foram: porcentagem, tempo médio, índice de velocidade e velocidade média de emergência das plântulas. A imersão das sementes em ácido sulfúrico entre 0,5 e 5 minutos proporcionou os maiores valores de emergência, sendo estatisticamente iguais entre si e diferentes da testemunha (0 minuto). Houve correlação positiva moderada entre porcentagem e índice de velocidade de emergência com os diferentes tempos de exposição das sementes ao ácido sulfúrico. Recomenda-se a escarificação química com ácido sulfúrico concentrado entre 0,5 e 5 minutos para a superação de dormência de sementes de S. silvestris.

Palavras-chave: Ácido sulfúrico; Escarificação química; Espécie florestal nativa; Sementes florestais

\section{Abstract}

Breaking the tegument dormancy of Senna silvestris (Vell.) H. S. Irwin \& Barneby seeds. Senna silvestris (Vell.) H. S. Irwin \& Barneby is a tree native to Brazil that has the potential to be used in urban forests and has seed coat-imposed dormancy. Considering the need to better understand native forest species, and more specifically the processes of overcoming seed dormancy, the objective of this study was to verify the behavior of $S$. silvestris seeds exposed to sulfuric acid (98\%), over different time periods $(0,0.5,3.0$, and 5.0 minutes), using four replications of 25 seeds and a completely randomized design. The parameters evaluated were the following: emergence percentage, mean emergence time, emergence rate index, and mean emergence rate of seedlings. The results of the experiment revealed that soaking the seeds in sulfuric acid between 0.5 and 5 minutes led to the highest emergence percentage, which was statistically equal for the seeds soaked in acid and different from the control treatment ( 0 minutes). There was a moderate positive correlation between emergence percentage and the emergence rate index of the different exposure times. It is therefore recommended that the chemical scarification with concentrated sulfuric acid be between 0.5 and 5 minutes to break the dormancy of $S$. silvestris seeds.

Key words: Chemical scarification; Forest seeds; Native forest species; Sulfuric Acid 


\section{Introdução}

A propagação comercial de espécies florestais via sementes exige que as mesmas apresentem boas características como uniformidade, alta porcentagem e rapidez no seu processo de germinação, além de alta sobrevivência para que sua produção se torne economicamente viável. Porém, nem sempre é possível a obtenção de sementes com todas as características desejáveis (PINEDO; FERRAZ, 2008) e a dormência de sementes, principalmente de leguminosas, representa um dos principais problemas encontrados para a produção de mudas florestais nativas (OLIVEIRA et al., 2003).

A dormência é caracterizada por sementes que não germinam mesmo sendo viáveis e expostas às condições ambientais favoráveis (FOWLER; BIANCHETTI, 2000). Carvalho e Nakagawa (2000) comentam que a dormência pode decorrer devido a fatores como impermeabilidade do tegumento à água e à troca de gases, embriões fisiologicamente imaturos ou rudimentares, presença de substâncias promotoras ou inibidoras de crescimento, embrião dormente, exigências diferenciadas de luz e temperatura, entre outras, sendo que a ocorrência deste fenômeno na natureza é um recurso utilizado pelas plantas produtoras de sementes para perpetuação de suas espécies, uma vez que impede que todas as sementes germinem na mesma época, aumentando sua chance de sobrevivência e diminuindo o risco de extinção. Contudo, isso pode se tornar um problema quando se pretende produzir mudas em viveiro, pois a dormência causa atraso e desuniformidade na germinação (BORGES et al., 1982; LOPES et al., 1998). Concomitantemente, diante da enorme biodiversidade do Brasil, existem poucas informações sobre as espécies nativas quanto as suas formas de propagação.

As sementes da espécie Senna silvestris (Vell.) H. S. Irwin \& Barneby apresentam dormência imposta pelo tegumento e, segundo Fowler e Bianchetti (2000), esse tipo de dormência é muito comum em sementes das famílias Fabaceae, Cannaceae, Convolvulaceae, Malvaceae e Chenopodiaceae. Conforme verificado por Rolston (1978), cerca de $85 \%$ de 260 espécies de leguminosas examinadas apresentaram sementes com tegumento total ou parcialmente impermeáveis à água, confirmando que este tipo de dormência é comum na família Fabaceae.
Há vários métodos de superação de dormência de sementes como, por exemplo, a escarificação química (utilização de ácidos) e mecânica (abrasão das sementes sobre uma superfície áspera), além de outros processos como a estratificação, choques de temperatura e imersão em água quente (VIEIRA; FERNANDES, 1997).

A eficiência do uso do ácido sulfúrico na superação de dormência de sementes florestais foi verificada em muitas espécies, como Senna macranthera (DC. ex Collad.) H.S.Irwin \& Barneby (ESCHIAPATIFERREIRA; PEREZ, 1997), Senna multijuga (Rich.) H.S.Irwin \& Barneby (PIVETA et al., 2010), Senna siamea (Lam.) H.S.Irwin \& Barneby (DUTRA et al., 2007), Bowdichia virgilioides Kunth (ALBUQUERQUE et al., 2007), Stryphnodendron adstringens (Mart.) Coville (MARTINS; NAKAGAWA, 2008), Apuleia leiocarpa (Vogel) J. F. Macbr. (BIANCHETTI et al., 1995), Schizolobium parahyba var. amazonicum (Huber ex Ducke) Barneby (CRUZ et al., 2007), Bauhinia monandra Kurz. (ALVES et al., 2000), Poincianella pyramidalis (Tul.) L.P.Queiroz (ALVES et al., 2007), entre outras. Entretanto, observa-se que o sucesso nos tratamentos com ácido sulfúrico está relacionado com o tempo de exposição das sementes ao mesmo e à espécie.

Senna silvestris é conhecida popularmente como ponçada ou fedegoso-do-mato, pertence à família botânica Fabaceae (Caesalpinioideae), tem porte arbóreo, atingindo de $5-20 \mathrm{~m}$ de altura, tronco curto de $20-30 \mathrm{~cm}$ de diâmetro. Fruto do tipo legume deiscente e achatado com 20-30 sementes negras. Planta pioneira, heliófila, ocorre em todo o Brasil, em matas pluviais, florestas semidecíduas e cerrados, tanto em terra firme como em várzea. A madeira é usada para caixotaria leve e para lenha. Aárvore apresenta florescimento exuberante e muito ornamental, tendo grande potencial para o cultivo no paisagismo, particularmente na arborização urbana (LORENZI, 2009).

Assim, considerando a necessidade de melhor conhecimento das espécies florestais nativas e, mais especificamente, dos processos de superação de dormência, esse trabalho teve por objetivo verificar o comportamento de sementes de $S$. silvestris submetidas a diferentes tempos de exposição ao ácido sulfúrico concentrado. 


\section{Material e Métodos}

O presente trabalho foi realizado no Viveiro de Produção de Mudas no Parque Zoobotânico da Universidade Federal do Acre (UFAC), Rio Branco, no interior de casa de vegetação $\left(9^{\circ} 57^{\prime} 11,38^{\prime}\right.$ 'S $67^{\circ} 52^{\prime} 28,54$ '”).

As sementes foram coletadas diretamente de árvores matrizes, localizadas no campus da UFAC, em Rio Branco-Acre, sendo levadas até o viveiro, beneficiadas, retirando-se manualmente as sementes dos frutos secos e, posteriormente, armazenadas em saco plástico no interior de câmara fria $\left(\approx 12^{\circ} \mathrm{C}\right)$ até o momento do teste de superação de dormência que ocorreu após três dias.

O delineamento estatístico utilizado foi o inteiramente casualizado, com quatro tratamentos e quatro repetições de 25 sementes, sendo a testemunha (sementes intactas) e exposição das sementes ao ácido sulfúrico durante três períodos de tempo: 0,5, 3 e 5 minutos.

O procedimento de superação de dormência ocorreu da seguinte forma: as sementes foram divididas em quatro subamostras de 100 unidades, as quais três delas foram imersas em ácido sulfúrico concentrado (98\%) num Becker, separadamente, nos períodos de tempo citados. Decorrido o tempo de imersão das sementes, o ácido foi neutralizado com uma base $\left(\mathrm{CaCO}_{3}\right)$, as sementes foram retiradas, lavadas em água corrente e secadas em papel absorvente.

Logo após a aplicação dos tratamentos de superação de dormência, ocorreu a semeadura em substrato areia, na profundidade de $1 \mathrm{~cm}$, sendo cada subamostra dividida em quatro repetições de 25 sementes, adotando espaçamento de $2 \times 2 \mathrm{~cm}$, dispostos em bandejas de plástico, no interior de casa de vegetação.

A irrigação aconteceu diariamente com irrigador plástico manual com o objetivo de manutenção da quantidade máxima de água que o substrato utilizado pode reter. A contagem das plântulas emergidas ocorreu diariamente, por um período de 23 dias.

Os parâmetros utilizados para avaliação das sementes foram: porcentagem de emergência (E\%), Índice de Velocidade de Emergência (IVE), Tempo Médio de Emergência (TME) e Velocidade Média de Emergência (VME) de plântulas, além de frequência relativa de emergência em relação ao tempo, conforme descritos por Santana e Ranal (2004).

Os resultados das porcentagens de emergência $(\% \mathrm{E})$ foram transformados, utilizando a equação arco seno $(\% \mathrm{E} / 100)^{1 / 2}$, para aproximação da distribuição normal da população (SANTANA; RANAL, 2004), porém, os resultados apresentados nas tabelas são os originais. Em seguida, os resultados foram submetidos à análise de variância, correlação, e as médias foram comparadas pelo teste de Tukey ao nível de 5\% de probabilidade. Para todas as análises foram utilizados os programas estatísticos Bioestat 5.0 (AYRES et al., 2007) e Assistat 7.5 (SILVA, 2008).

\section{Resultados e Discussão}

Foi observada diferença significativa entre os tempos de imersão das sementes no ácido sulfúrico e a testemunha para todos os parâmetros de avaliação das sementes (Tabela 1).

TABELA 1: Medidas de emergência de plântulas de Senna silvestris: Emergência (E); Índice de Velocidade de Emergência (IVE); Tempo Médio de Emergência (TME); Velocidade Média de Emergência (VME).

\begin{tabular}{|c|c|c|c|c|}
\hline TRATAMENTOS & E $(\%)$ & IVE (plântulas dia-1) & TME (dias) & VME $\left(\right.$ dia $\left.^{-1}\right)$ \\
\hline Testemunha (0min) & $14 \pm 2,0 \mathrm{c}$ & $0,4017 \pm 0,09 \mathrm{c}$ & $9,6 \pm 2,2 \mathrm{~b}$ & $0,1072 \pm 0,02 \mathrm{~b}$ \\
\hline $0,5 \mathrm{~min}$ & $99 \pm 2,0 \mathrm{a}$ & $3,4988 \pm 0,13 \mathrm{a}$ & $7,4 \pm 0,5 \mathrm{ab}$ & $0,1348 \pm 0,01 \mathrm{ab}$ \\
\hline 3,0min & $81 \pm 6,0 \mathrm{a}$ & $3,1011 \pm 0,40 \mathrm{a}$ & $6,9 \pm 0,7 \mathrm{a}$ & $0,1470 \pm 0,02 \mathrm{a}$ \\
\hline $5,0 \mathrm{~min}$ & $97 \pm 3,8 \mathrm{a}$ & $3,8668 \pm 0,26 \mathrm{a}$ & $6,9 \pm 0,5 \mathrm{a}$ & $0,1459 \pm 0,01 \mathrm{a}$ \\
\hline Valor de F & $112,6 * *$ & $155,4 * *$ & $4,57 * *$ & $6,33 * *$ \\
\hline${ }^{1} \mathrm{CV}(\%)$ & 8,70 & 9,30 & 15,99 & 11,00 \\
\hline${ }^{2} \mathbf{p}$ & $<0,001$ & $<0,001$ & 0,023 & 0,008 \\
\hline
\end{tabular}

**Teste F significativo a 1\% de probabilidade; as médias seguidas pelas mesmas letras não diferem entre si significativamente, pelo teste de Tukey, ao nível de $5 \%$ de probabilidade; ${ }^{1} \mathrm{CV}$ : coeficiente de variação; ${ }^{2}$ Probabilidade. 
As maiores porcentagens de emergência de plântulas ocorreram quando as sementes foram submetidas aos tratamentos de imersão no ácido sulfúrico. A imersão por 0,5 e 5 minutos foi responsável por quase $100 \%$ de emergência das plântulas e foram estatisticamente iguais entre si, apresentando ainda baixíssimos tempos médios de emergência. Já as sementes que não foram imersas em ácido (testemunha) apresentaram tempo médio 9,6 dias para emergência de apenas $14 \%$ das plântulas.

Rodrigues et al. (2009) constataram que para a espécie Adenanthera pavonina L. a escarificação química com ácido sulfúrico por 22 minutos permitiu um maior número de sementes germinadas em menor tempo. Para a espécie $S$. adstringens, Martins e Nakagawa (2008) encontraram teores de água mais elevados nas sementes após imersão em ácido sulfúrico, quando comparado com os tratamentos de escarificação mecânica e imersão em água quente, o que se deve à maior permeabilidade do tegumento, favorecendo a entrada de água na semente. Além disso, os autores indicaram a imersão em ácido por 60 minutos para a superação de dormência das sementes dessa espécie.

Segundo Nascimento et al. (2009), a escarificação química com ácido sulfúrico em sementes de Parkia platycephala Benth. entre 15 e 45 minutos foi eficiente para superar a dormência imposta pelo tegumento. Por sua vez, estudando a espécie Libidibia ferrea var. leiostachya (Benth.) L. P. Queiroz, Biruel et al. (2007) constataram que, para sementes armazenadas, a imersão por 10 minutos em ácido sulfúrico foi o suficiente para a superação da dormência. Por outro lado, para sementes recém-colhidas, o tempo necessário para a superação da dormência tegumentar é maior e a imersão por 20 a 30 minutos favoreceu a porcentagem de germinação.

No presente estudo, a imersão em ácido sulfúrico entre 0,5 e 5 minutos promoveu os valores mais elevados do índice de velocidade e velocidade média de emergência (Tabela 1). De acordo com Santana e Ranal (2004), esses parâmetros (com valores elevados) indicam a ocorrência de sementes mais vigorosas e com maior capacidade de formar plantas normais em campo, diferindo estatisticamente do tratamento testemunha que proporcionou valores bem inferiores, quando comparado com os outros tratamentos.
A emergência e o índice de velocidade de emergência se diferenciaram ao longo do tempo entre os tratamentos pré-germinativos e a testemunha como se pode observar pela Figura 1.

As sementes que foram escarificadas com ácido sulfúrico obtiveram emergência rápida e uniforme e não apresentaram plântulas defeituosas em nenhum dos tempos de imersão no ácido, mostrando-se eficiente para a superação da dormência de sementes de $S$. silvestris.

A emergência das plântulas formadas após germinação das sementes submetidas aos três tempos de imersão no ácido iniciou-se rapidamente no quarto dia da semeadura, estabilizando-se entre o décimo primeiro e o décimo quinto dia após a primeira emergência, diferentemente das sementes intactas que apresentaram baixa e lenta emergência ao longo do tempo, segundo o índice de velocidade de emergência (Figura 1).

Alves et al. (2006) obtiveram elevado valor de Índice de Velocidade de Emergência de Zizyphus joazeiro Mart. quando as sementes foram imersas por 100 minutos em ácido sulfúrico concentrado, sendo responsável pelo vigor máximo das sementes. Comportamento semelhante também foi verificado por Albuquerque et al. (2007), quando as sementes de Bowdichia virgilioides Kunth. foram imersas no ácido por 4,8 e 12 minutos.

Em sementes de $S$. macranthera, a escarificação com ácido sulfúrico por 50 minutos se mostrou como o método mais eficiente para a superação da dormência quando comparado com outros tratamentos, o qual apresentou a maior velocidade de germinação. (ESCHIAPATI-FERREIRA; PEREZ, 1997).

Outra maneira de verificar o comportamento das sementes neste processo ao longo do tempo é através da frequência relativa de emergência das plântulas (SANTANA; RANAL, 2004) como se pode verificar pela Figura 2. As sementes escarificadas com ácido sulfúrico apresentaram comportamento germinativo diferente da testemunha ao longo do tempo. Apesar de os maiores picos de emergência terem sido no mesmo período, no sétimo dia, em todos os tratamentos, a emergência de apenas $5 \%$ das plântulas foi responsável por esse pico no tratamento testemunha. Por outro lado, 
FIGURA 1: Porcentagem de emergência acumulada de plântulas de Senna silvestris (Vell.) H. S. Irwin \& Barneby (Fabaceae) nos diferentes tempos de exposição das sementes ao ácido sulfúrico.

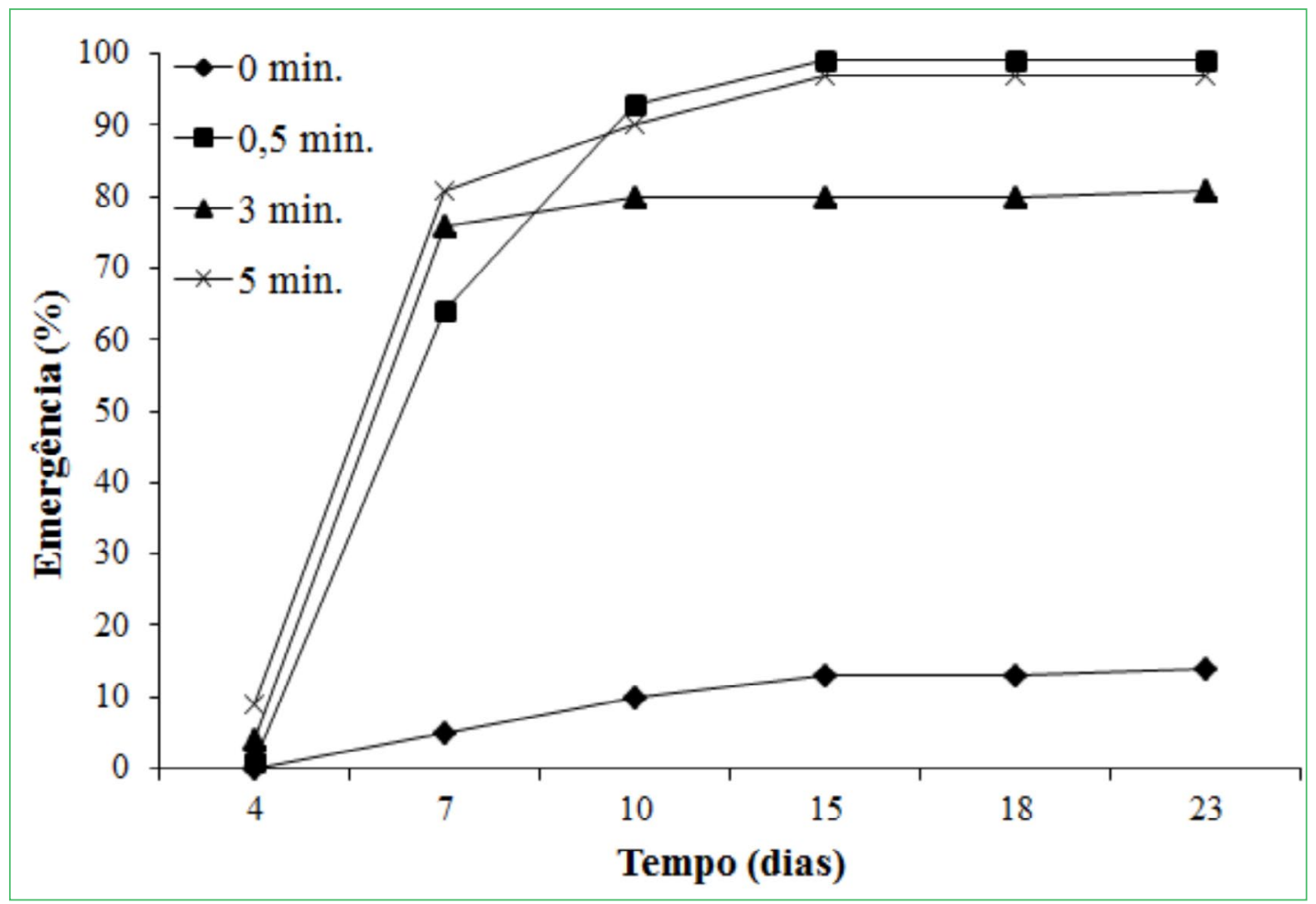

FIGURA 2: Polígonos de frequência relativa da emergência de plântulas de Senna silvestris (Vell.) H. S. Irwin \& Barneby (Fabaceae), oriundas de sementes submetidas a diferentes tempos de exposição ao ácido sulfúrico.

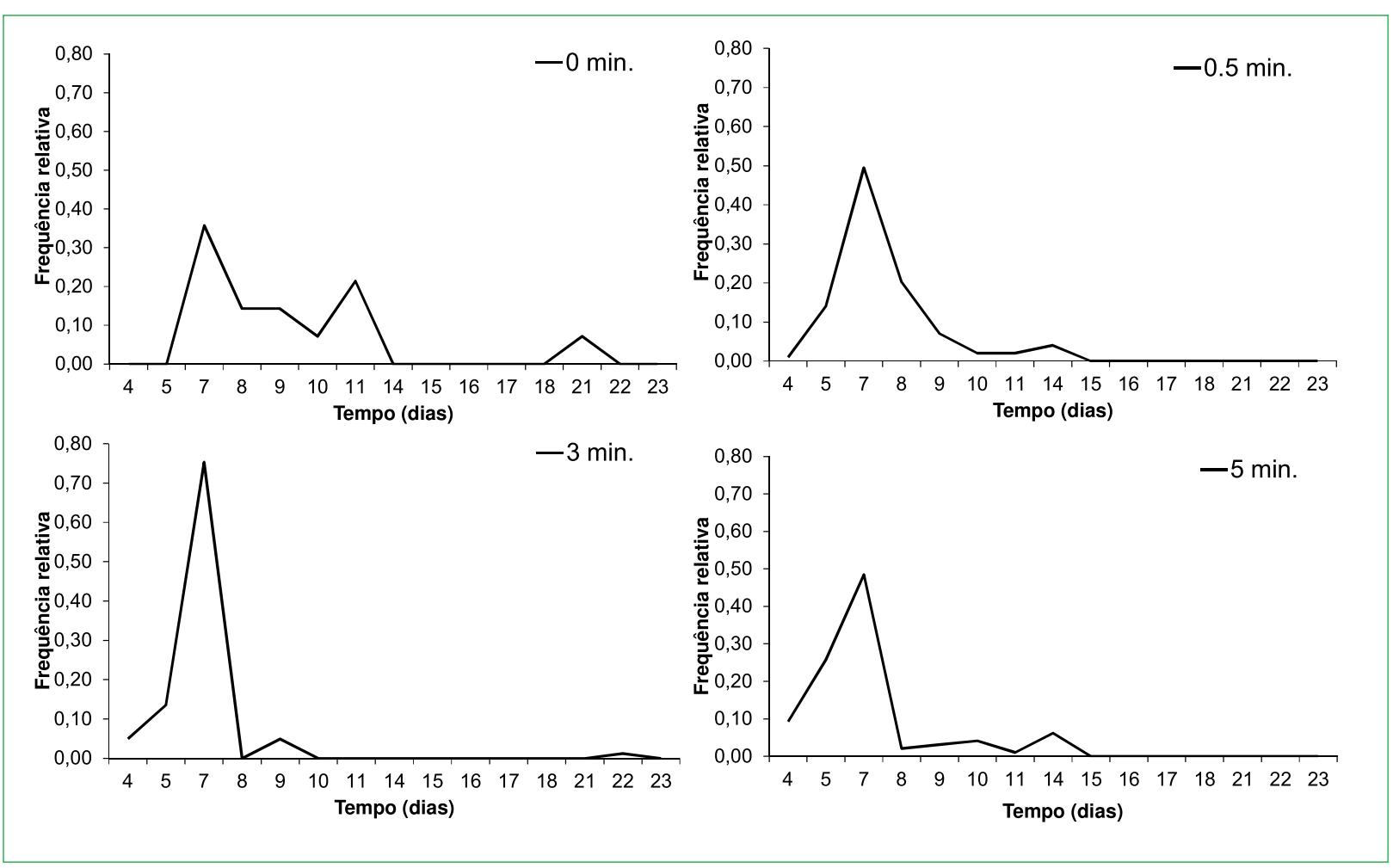


as sementes que permaneceram imersas no ácido por 0,5 , 3 e 5 minutos já apresentavam, nesse mesmo período, emergência de 49, 61 e 47\%, respectivamente.

Os tratamentos pré-germinativos proporcionaram rápida emergência de plântulas e apenas um pico de emergência, que ocorreu no sétimo dia da semeadura. $\mathrm{O}$ tratamento testemunha apresentou vários picos de emergência ao longo do tempo, possivelmente relacionados às sementes apresentarem tempos diferentes para a absorção água do substrato e iniciarem os processos metabólicos.

A partir da análise de correlação linear de Pearson (Figura 3) entre os parâmetros Porcentagem de Emergência e Índice de Velocidade de Emergência com os diferentes tempos de exposição das sementes ao ácido sulfúrico, verificou-se que houve correlação positiva moderada entre a emergência $(r=0,57)$ e os tempos de exposição das sementes ao ácido, sendo o resultado semelhante obtido para os índices de velocidade de emergência $(r=0,66)$.

Diante disso, a escarificação das sementes por ácido sulfúrico permitiu alta porcentagem e velocidade de emergência com apenas 0,5 minuto de imersão.

O ácido sulfúrico se mostrou eficiente insumo na superação da dormência tegumentar de sementes de $S$. silvestris, proporcionando maiores valores para todos os parâmetros de emergência de plântulas avaliados. Dessa forma, recomenda-se a escarificação química com ácido sulfúrico entre 0,5 e 5 minutos para superação de dormência de sementes da espécie estudada.

FIGURA 3: Correlação de Pearson (r) entre \%E (a) e IVE (b) com os diferentes tempos de exposição das sementes de S. silvestris (Vell.) H. S. Irwin \& Barneby (Fabaceae) ao ácido sulfúrico.

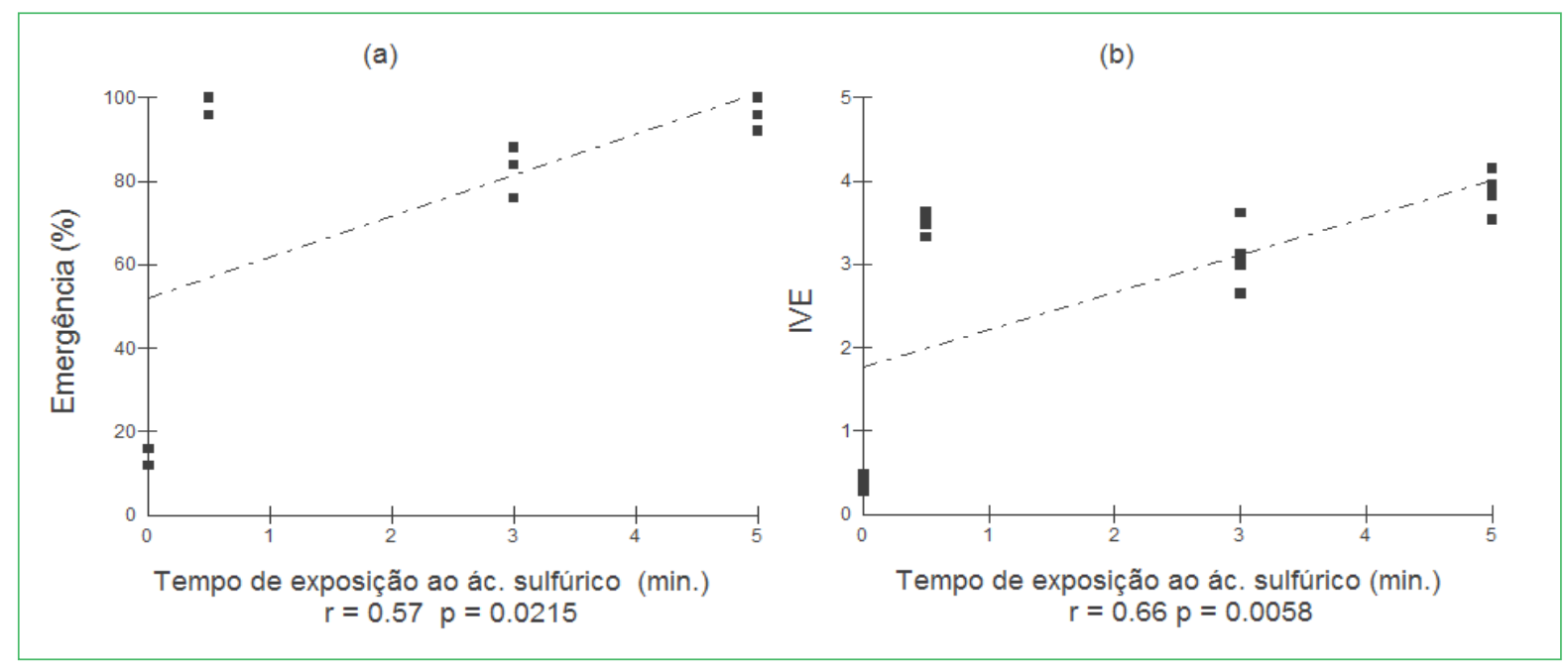




\section{Referências}

ALBUQUERQUE, K. S.; GUIMARÃES, R. M. ALMEIDA, Í. F. de; CLEMENTE, A. da C. S. Métodos para a superação da dormência em sementes de sucupira-preta (Bowdichia virgilioides KUNTH.). Ciência \& Agrotecnologia, Lavras, v. 31, n. 6, p. 17161721, 2007.

ALVES, E. U.; BRUNO, R. de L. A.; OLIVEIRA, A. P. de; ALVES, A. U.; ALVES, A. U. Ácido sulfúrico na superação da dormência de unidades de dispersão de juazeiro (Zizyphus joazeiro Mart.). Revista Árvore, Viçosa, v. 30, n. 2, p. 187-195, 2006.

ALVES, E. U.; CARDOSO, E. de A.; BRUNO, R. de L. A.; ALVES, A. U.; ALVES, A. U. GALINDO, E. A.; BRAGA JUNIOR, J. M. Superação da dormência em sementes de Caesalpinia pyramidalis Tul. Revista Árvore, Viçosa, v. 31, n. 3, p. 405-415, 2007.

ALVES, M. da C. S.; MEDEIROS-FILHO, S.; ANDRADENETO, M.; TEÓFILO, E. M. Superação da dormência em sementes de Bauhinia monandra Britt. e Bauhinia ungulata L. Caesalpinoideae. Revista Brasileira de Sementes, Lavras, v. 22, n. 2, p. 139-144, 2000.

AYRES, M.; AYRES JR., M.; AYRES, D. L.; SANTOS; A. S. dos. 2007. Bioestat 5.0. - Aplicações estatísticas nas áreas das ciências biológicas e médicas 2007. Belém: Sociedade Civil Mamirauá/MCT-CNPq. Disponível em <http://www.mamiraua. org.br/download/Default.aspx?dirpath=e: $\backslash$ home $\backslash$ mamiraua $\backslash W e b \backslash$ download $\backslash$ BioEstat $\% 205 \% 20$ Portugues \& tipo $=$ diretorio $>$. Acesso em: 15 junho 2010

BIANCHETTI, A.; MARTINS, E. G.; FOWLER, J. A. P.; RAMOS, A.; ALVES, V. F. Tratamentos pré-germinativos para sementes de gráfia (Apuleia leiocarpa). Colombo: Embrapa-CNPF, 1995. 1 p.(Comunicado Técnico, 2).

BIRUEL R. P.; AGUIAR, I. B.; de. PAULA, R. C. de. Germinação de sementes de pau-ferro submetidas a diferentes condições de armazenamento, escarificação química, temperatura e luz. Revista Brasileira de Sementes, Lavras, v. 29, n. 3, p. 151-159, 2007.

BORGES, E. E. de L.; BORGENS, R. de C. G.; CANDIDO, J. F.; GOMES, J. M. Comparação de métodos de quebra de dormência em sementes de copaíba. Revista Brasileira de Sementes, Lavras, v. 4, n. 1, p. 9-12, 1982.

CARVAlHO, N. M.; NAKAGAWA, J. Sementes: ciência, tecnologia e produção. 4 ed. Jaboticabal: FUNEP, 2000. 429 p.

CRUZ, E. D.; CARVALHO, J. E. U. de.; QUEIROZ, R. J. B. Scarification with sulphuric acid of Schizolobium amazonicum Huber ex Ducke seeds - Fabaceae. Scientia Agricola, Piracicaba, v. 64, n. 3, p. 308-313, 2007.

DUTRA, A. S.; MEDEIROS FILHO, S.; TEÓFILO, E. M.; DINIZ, F. O. Germinação de sementes de Senna siamea (Lam.) H. S. Irwin e Barneby - Caesalpinoideae. Revista Brasileira de Sementes, Lavras, v. 29, n. 1, p. 160-164, 2007.

ESCHIAPATI-FERREIRA, M. S.; PEREZ, S. C. J. G. A. Tratamentos para superar a dormência de sementes de Senna macranthera (Collad.) Irwin et Barn. (Fabaceae-Caesalpinoideae). Revista Brasileira de Sementes, Lavras, v. 19, n. 2, p. 230-236, 1997.
FOWLER, A. J. P.; BIANCHETTI, A. Dormência em sementes florestais. Colombo: Embrapa Florestas, 2000, 27 p. (Documentos, 40).

LOPES, J. C.; CAPUCHO, M. T.; KROHLING, B.; ZANOTTI, P. Germinação de sementes de espécies florestais de Caesalpinia ferrea Mart. Ex Tul. Leiostachya Benth., Cassia grandis L. e Samanea saman Merril, após tratamentos para superar a dormência. Revista Brasileira de Sementes, Lavras, v. 20, n. 1, p. 80-86, 1998. LORENZI, H. Árvores brasileiras: manual de identificação e cultivo de plantas arbóreas nativas do Brasil. Vol. 3. Nova Odessa: Instituto Plantarum, 2009. 384 p.

MARTINS, C. C.; NAKAGAWA, J. Germinação de sementes de Stryphnodendron adstringens (Mart.) Coville de diferentes origens submetidas a tratamentos para superação de dormência. Revista Árvore, Viçosa, v. 32, n. 6, p. 1059-1067, 2008.

NASCIMENTO I. L.; ALVES, E. U.; BRUNO, R. de L. A.; GONÇALVES, E. P.; COLARES, P. N. Q.; MEDEIROS, M. S. de. Superação da dormência em sementes de faveira (Parkia platycephala Benth). Revista Árvore, Viçosa, v. 33, n. 1, p. 35-45, 2009.

OliVEIRA, L. M.; DAVIDE, A. C.; CARVAlHO, M. L. M. de. Avaliação de métodos para quebra da dormência e para a desinfestação de sementes de canafístula (Peltophorum dubium (Sprengel) Taubert. Revista Árvore, Viçosa, v. 27, n. 5, p. 597603, 2003.

PINEDO, G. J. V.; FERRAZ, I. D. K. Hidrocondicionamento de Parkia pendula [BENTH ex WALP]: sementes com dormência física de árvore da Amazônia. Revista Árvore, Viçosa, v. 32, n. 1, p. 39-49, 2008.

PIVETA, G.; MENEZES, V. O.; PEDROSO, D. C.; MUNIZ, M. F. B.; BLUME, E. WIELEWICKI, A. P. Superação de dormência na qualidade de sementes e mudas: influência na produção de Senna multijuga (L. C. Rich) Irwin \& Barneby. Acta Amazonica, Manaus, v. 40, n. 2, p. 281-288, 2010.

RODRIGUES A. P. D. C.; KLEBER, A.; OLIVEIRA, M. de; LAURA, V. A.; YAMAMOTO, C. R.; CHERMOUTH, K. da S.; FREITAS, M. H. de. Tratamentos para superação da dormência de sementes de Adenanthera pavonina L. Revista Árvore, Viçosa, v. 33, n. 4, p. 617-623, 2009.

ROLSTON, M. P. Water impermeable seed dormancy. The Botanical Review, v. 44, p. 365-396, 1978.

SANTANA, D. de G.; RANAL, M. A.; Análise da germinação. Um enfoque estatístico. Brasília: Universidade de Brasília, 2004. 248p.

SILVA, F. de A. S. e. Assistat 7.5, 2008. Departamento de Engenharia Agrícola, UFCG. Disponível em: <http://www.assistat. com>. Acesso em: 18 jan. 2011.

VIERA, I. G.; FERNANDES, G. D. Métodos de quebra de dormência de sementes. Informativo sementes IPEF, Piracicaba, 1997. 